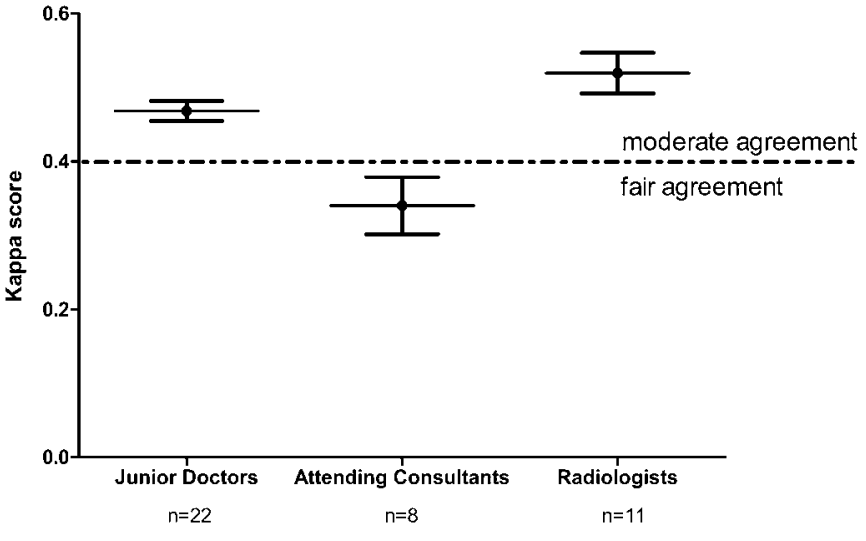

Abstract P251 Figure 1 Consistency between doctors when reporting CXRs in the context of possible CAP ( $\kappa$ with $95 \% \mathrm{Cl}$ ).

Conclusions In the context of possible pneumonia, the CXR was not consistently reported by any group. Junior doctors were more consistent than attending consultants and radiologists were most consistent. A possible explanation for these differences is that junior doctors, by necessity, have developed similar ideas of what they will consider pneumonic where as consultants who less frequently make the initial diagnostic decision vary in their criteria for diagnosing pneumonia. This study does not present a "gold standard" interpretation and therefore does not address the issue of accuracy but it does raise questions about to what extent the CXR ever be regarded as a "reliable" diagnostic test.

\section{COPD and drugs: new and old concepts P252 ONCE-DAILY NVA237 IMPROVES SYMPTOMS, AND REDUCES COPD EXACERBATIONS AND ASSOCIATED HOSPITALISATIONS: THE GLOW1 TRIAL}

\section{doi:10.1136/thoraxjnl-2011-201054c.252}

${ }^{1} \mathrm{~A}$ D'Urzo, ${ }^{2} \mathrm{~J}$ A van Noord, ${ }^{3} \mathrm{C}$ Martin, ${ }^{3} \mathrm{R}$ Horton, ${ }^{4} \mathrm{D}$ Banerij, ${ }^{4} Y \mathrm{Lu},{ }^{3} \mathrm{~V}$ K T Alagappan, ${ }^{3} \mathrm{~T}$ Overend. ${ }^{1}$ Department of Family and Community Medicine, University of Toronto, Ontario, Canada; ${ }^{2}$ Atrium Medisch Centrum, Heerlen, The Netherlands; ${ }^{3}$ Novartis Horsham Research Centre, Horsham, West Sussex, UK; ${ }^{4}$ Novartis Pharmaceuticals Corporation, East Hanover, New Jersey, USA

Introduction Symptoms profoundly impact daily life of COPD patients. We assessed the influence of the once-daily (qd) long-acting muscarinic antagonist (LAMA) NVA237 (glycopyrronium bromide) on symptoms and exacerbations in patients with moderate-tosevere COPD.

Methods Patients were randomised $(2: 1)$ to 26 weeks double-blind treatment with NVA237 $50 \mu \mathrm{g}$ qd or placebo (PBO) via a single-dose dry powder inhaler (Breezhaler ${ }^{\circledR}$ device). Efficacy was assessed by bronchodilation (trough $\mathrm{FEV}_{1}$ at Week 12), breathlessness on the transition dyspnoea index (TDI), HRQoL via the St. George's Respiratory Questionnaire (SGRQ), and rescue medication use. The effect on COPD exacerbations and related hospitalisations was also assessed.

Results 822 patients were randomised; $80.5 \%$ completed. NVA237 significantly increased total TDI focal score vs PBO at Week 26 (difference $1.04,95 \%$ CI 0.583 to $1.504 ; \mathrm{p}<0.0001$ ); exceeding the minimum clinically important difference ([MCID] $=1$ point). Significantly more patients achieved MCID in TDI score with NVA237 (61.3\% vs $48.3 \%$; OR $1.74,95 \%$ CI 1.249 to 2.415 ; $\mathrm{p}=0.001)$. SGRQ total score was significantly reduced with NVA237 $(-2.81 ; p=0.004) ; \%$ of patients achieving a clinically meaningful improvement in SGRQ (=4 point reduction) was significantly higher with NVA237 (56.8\% vs 46.3\%; OR 1.58, 95\% CI 1.138 to
2.196; $\mathrm{p}=0.006)$. NVA237 significantly reduced rescue medication use at Week 26 ( -0.46 puffs/day, $p=0.005)$. NVA237 significantly prolonged time to first moderate/severe COPD exacerbation by $31 \%$ (HR 0.69, 95\% CI 0.50 to $0.949 ; \mathrm{p}=0.023$ ) and time to first severe COPD exacerbation necessitating hospitalisation (HR $0.35,95 \% \mathrm{CI}$ 0.141 to $0.857 ; p=0.022$ ). NVA237 significantly reduced hospitalisations due to COPD exacerbation (OR 0.34; $\mathrm{p}=0.024$ ).

Conclusion Once-daily NVA237 provided significant improvements in dyspnoea and SGRQ total score, with lower rescue medication use, and reduced risk of exacerbation and associated hospitalisations vs $\mathrm{PBO}$.

\section{P253 NVA237 ONCE DAILY OFFERS RAPID AND CLINICALLY MEANINGFUL BRONCHODILATION IN COPD PATIENTS THAT IS MAINTAINED FOR 24 H: THE GLOW1 TRIAL}

doi:10.1136/thoraxjnl-2011-201054c.253

${ }^{1} \mathrm{~T}$ D'Urzo, ${ }^{2} \mathrm{G}$ Ferguson, ${ }^{3} \mathrm{C}$ Martin, ${ }^{3} \mathrm{~V}$ K T Alagappan, ${ }^{4} \mathrm{D}$ Banerji, ${ }^{4} \mathrm{Y}$ Lu, ${ }^{3} \mathrm{R}$ Horton, ${ }^{3} \mathrm{~T}$ Overend. ${ }^{1}$ Department of Family and Community Medicine, University of Toronto, Ontario, Canada; ${ }^{2}$ Pulmonary Research Institute of Southeast Michigan, Livonia, Michigan, USA; ${ }^{3}$ Novartis Horsham Research Centre, Horsham, West Sussex, UK; ${ }^{4}$ Novartis Pharmaceuticals Corporation, East Hanover, New Jersey, USA

Introduction NVA237 (glycopyrronium bromide) is an inhaled longacting muscarinic antagonist (LAMA) in development for the oncedaily (qd) treatment of COPD. The GLOW1 study evaluated the efficacy and safety of NVA237 in patients with moderate-to-severe COPD.

Methods Patients were randomised (2:1) to 26 weeks double-blind treatment with NVA237 $50 \mu \mathrm{g}$ qd or placebo (PBO). Study drugs were administered via a single-dose dry powder inhaler (Breezhaler ${ }^{\circledR}$ device). Primary efficacy endpoint: trough $\mathrm{FEV}_{1}$ (mean of $23 \mathrm{~h}$ $15 \mathrm{~min}$ and $23 \mathrm{~h} 45 \mathrm{~min}$ post-dose values) vs $\mathrm{PBO}$ after 12 weeks.

Results 822 patients were randomised; mean age was 63.9 years, mean post-bronchodilator $\mathrm{FEV}_{1}$ was $55 \%$ predicted. $80.5 \%$ completed the study. At Week 12 there was a statistically significant and clinically relevant difference between NVA237 vs PBO in mean trough $\mathrm{FEV}_{1}(108 \mathrm{ml} ; \mathrm{p}<0.001)$. Trough $\mathrm{FEV}_{1}$ was also significantly higher at Day 1 and Week 26 (treatment difference: $105 \mathrm{ml}$ and $113 \mathrm{ml}$, respectively; $\mathrm{p}<0.001$ ). Serial spirometry in a subpopulation of patients showed statistically superior $(p<0.001)$ and clinically meaningful improvements in $\mathrm{FEV}_{1}$ with NVA237 vs $\mathrm{PBO}$ at all timepoints on Day 1, Week 12 and Week 26. NVA237 had a rapid onset of action with an increased $\mathrm{FEV}_{1}$ of $93 \mathrm{ml}$ at $5 \mathrm{~min}$ and $144 \mathrm{ml}$ at $15 \mathrm{~min}$ vs $\mathrm{PBO}$ after the first dose on Day $1(\mathrm{p}<0.001)$. Overall, the incidence of adverse events (AEs) was similar between treatment groups (NVA237: 57.5\%; PBO: 65.2\%). Serious AEs were reported by $7.5 \%$ of NVA237- vs $9.0 \%$ of PBO-treated patients.

Conclusion NVA237 $50 \mu \mathrm{g}$ once daily was generally safe and well tolerated. Improvements in bronchodilation were rapid, clinically meaningful and maintained for $24 \mathrm{~h}$ throughout the study.

\section{P254 NVA237 ONCE DAILY IMPROVES EXERCISE ENDURANCE IN PATIENTS WITH COPD FROM THE FIRST DOSE: THE GLOW3 TRIAL}

doi:10.1136/thoraxjn|-2011-201054c.254

${ }^{1} \mathrm{D}$ Singh, ${ }^{2} \mathrm{~K}$ Beeh, ${ }^{3} \mathrm{~A}$ Drollmann, ${ }^{3} \mathrm{~L}$ Di Scala, ${ }^{4} \mathrm{R}$ Smith. ${ }^{1}$ University of Manchester, Medicines Evaluation Unit, Manchester, UK; ${ }^{2}$ insaf Respiratory Research Institute, Wiesbaden, Germany; ${ }^{3}$ Novartis Pharma AG, Basel, Switzerland; ${ }^{4}$ Novartis Horsham Research Centre, West Sussex, UK

Introduction The fundamental characteristics of COPD are exertional dyspnoea and exercise limitation, which are associated with 